\title{
ОСОБЕННОСТИ РАЗВИТИЯ УЧЕТА И КОНТРОЛЯ В УСЛОВИЯХ ЦИФРОВОЙ ЭКОНОМИКИ
}

\author{
(C) 2021 Савин A. A. \\ кандидат экономических наук, профессор Департамента аудита и корпоративной отчетности \\ Финансовый университет при Правительстве Российской Федерации, Россия, Москва \\ E-mail: aasavin@fa.ru
}

Новый сложный мир стремительно захватывает все сферы жизни. Цифровизация меняет подход к управлению страной, городом, бизнесом и собственной жизнью. Создается новая реальность, где вся информация о мире переносится в язык нулей и единиц, где нет отличий оригинала от копии, где данные не устаревают и не исчезают. Будущее описывают понятием VUCA, которое включает в себя изменчивость, неопределенность, сложность и неоднозначность. Появление новых более сложных задач будет предполагать новый подход к их решению. Нельзя говорить исключительно об изменении траектории учета и контроля, для начала необходимо понять, какие тренды существуют и определяют образ будущего.

Ключевые слова: учет, анализ, аудит, налогообложение, право, взаимосвязь

Повышенное внимание к экологии набирает обороты, человечество начинает осознавать себя частью биосистемы в целом, видение становится более комплексным, человек анализирует какие губительные последствия могут быть при потребительском подходе не только для своего поколения, но и на сотни лет вперед. Глобализация товаров, услуг, знаний, культур занимает важное место. Сегодня мы можем общаться с представителями других национальностей с помощью сети на одном языке, играть в одни компьютерные игры, читать книги зарубежных партнеров. Границы стираются. Происходит изменение модели семьи, женщина является активным участником экономики. Продолжительность жизни увеличивается, пенсионеры ведут активный и полноценный образ. Развитие сетевого общества на основе blockchain, роботизация, развитие автономных сетей, и цифровизация происходят в ускоренном режиме. К 2021 году трафик интернета по сравнению с 2005 годом вырастет в 127 раз (по данным Cisco). Интернет становится сетью всего. В 2017 году Илон Маск объявил о создании компании Neurolink, которая будет работать над созданием полноценного интерфейса «мозг-компьютер». Цель - увеличение производительности умственного труда за счет интеграции мозга человека и вычислительных машин. Технологии искусственного интеллекта самостоятельно будут решать сложные задачи. Образ «Индустрии 4.0» был представлен на Ганноверской промышленной ярмарке в 2011 году, четвертую промышленную революция характеризуют повсеместной цифровизацией, стиранием граней между физическими, цифровыми и биологическими сферами. Замена однотипных ручных операций с помощью роботизации, повсеместное распространение беспилотного транспорта, сегодня уже тестируются модели машин. Прямой контакт между устройствами предполагает «удаление» посредников в цепочке работы.

Жизненный цикл профессий сокращается. Сейчас ориентир идет не на прогноз профессий будущего, а на формирование компетенций и навыков, владея которыми, человек сможет гармонично сосуществовать в новой экосреде, будет готов к переобучению и освоению всего нового. ЭВМ получили жизнь в середине прошлого века, ПК в 70-е годы. Разработка программного обеспечения повлекла за собой появление новых профессий. В 2016 году компания Х.аi создала виртуального секретаря Ату, который уже вполне готов выполнять элементарные поручения, и даже вести коммуникация с контрагентами. Каждый из нас наблюдает изменения ежедневно. Сегодня, чтобы полететь в другую страну, не нужен турагент, который подбирает и бронирует полет, жилье, мы сами в состоянии подобрать удобный вариант. Сегодня уже не нужно стоять в очереди на вокзале за билетом в кассу на поезд, покупка занимает буквально несколько минут. Сегодня снять квартиру не составит труда, и нам не нужен риелтор. В магазинах появляются 
кассы самообслуживания. Раньше человек выступал в роли посредника между различными системами, сегодня все больше его заменяет машина. И справляется она не плохо. Мир связан сетями, отпадает необходимость работать 5/2 на одну организацию, когда можно найти свое дело и продвигать его с помощью интернета. В базе данных информацией обладают сразу все, ее изъятие довольно проблематично. Посредники в сделках исчезают, что приводит к глобальным изменениям в государственной и корпоративной бюрократии и к полномасштабной демократизации финансового сектора. В новом мире не будет профессий, где будет достаточно овладеть навыками в детстве и не переучиваться; не будет работы, основанной на выполнении однотипных операций на производстве; будет горизонтальная иерархия, где ответственность за деятельность организации лежит не на одном человеке, и где каждый имеет право решать; не будет рутинной работы за компьютером, когда понятно что, откуда и куда надо скопировать; не будет четкого разграничения между личным и рабочим временем; будут профессии с работой в виртуальной реальности, а дополненная реальность станет привычным явлением, творческая реализация будет совмещаться с основной деятельностью. Возникают профессии направленные на управление на основе ИИ. Рабочие места будут изменяться в разном темпе в разных секторах, некоторые уже устарели, а в некоторых только начались деформации.

Возникает необходимость к адаптации. Выбирая профессию человеку не нужно быть ориентированным на высокую оплату и пер- спективность, он должен понять смысл своей деятельности и своей жизни. Планируется появление безусловного дохода, где каждый будет иметь средства к существованию.

Принято разделять hard skills и soft skills. Под жесткими навыками подразумевают деятельность с конкретным ощутимым результатом.

На первый план начинают выходить soft skills. Почему? Все просто! Человеку нужен человек. Представить мир роботов и компьютерных систем можно, но как определить роль человека в новой системе. В Японии можно нанять друга на время за деньги, и провести с ним время. а социальные сети нам уже заменили личный контакт. Критическое и системное мышление позволяет ставить под сомнение всю поступающую информацию, анализировать ее, и принимать стратегию ее принятия. Творческое мышление (креативность)- придумывать новые способы решения задач, изобретать и импровизировать. Коммуникация и кооперация - способность решить проблему или задачу путем совместных усилий, это не общение между друзьями, а взаимоотношения между коллегами. Эмоциональный интеллект- подразумевает постижение собственных и чужих ощущений и эмоций, состояния, проявление эмпатии. Невозможно решить проблему, если думать также, как те, кто ее создал. Цена лидерства-ответственность. Лидерство - это не обязательно генеральный директор, это человек, способный координировать, направлять, понимать.

Профессия бухгалтера включает в себя довольно много компетенций и навыков. От коммуникации зависит слаженность работы вну-

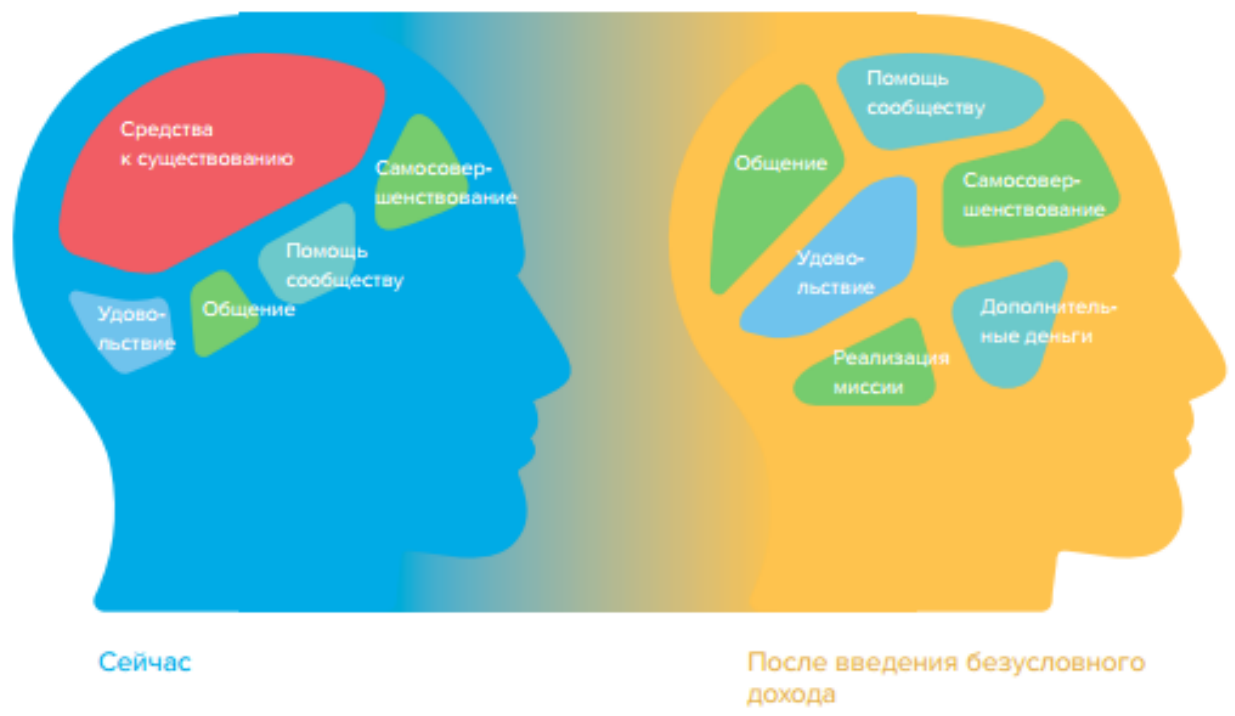


Базовые навыки XXI века

\begin{tabular}{|c|c|}
\hline $\begin{array}{l}\text { Концентрация } \\
\text { и управление вниманием }\end{array}$ & $\begin{array}{l}\text { Необходимы, чтобы справляться с информационной перегрузкой, управлять } \\
\text { сложной техникой. }\end{array}$ \\
\hline $\begin{array}{l}\text { Эмоциональная } \\
\text { грамотность }\end{array}$ & $\begin{array}{l}\text { Аффективная область приобретает все большую значимость в работе. } \\
\text { Понимание своих эмоций, эмпатия, сочувствие помогут сохранить себя } \\
\text { и взаимодействовать с другими. }\end{array}$ \\
\hline $\begin{array}{l}\text { Цифровая } \\
\text { грамотность }\end{array}$ & $\begin{array}{l}\text { Способность работать в цифровой среде, в том числе AR и VR, будет } \\
\text { столь же востребована, как способность писать и читать. }\end{array}$ \\
\hline $\begin{array}{l}\text { Творчество, } \\
\text { креативность }\end{array}$ & $\begin{array}{l}\text { При автоматизации рутинной деятельности на любой работе будет все } \\
\text { больше необходимости мыслить нестандартно и создавать новое. }\end{array}$ \\
\hline $\begin{array}{l}\text { Экологическое } \\
\text { мышление }\end{array}$ & $\begin{array}{l}\text { Понимать связность мира, воспринимать свою деятельность в контексте } \\
\text { всей экосистемы, поддерживать эволюционные процессы. }\end{array}$ \\
\hline Кросскультурнсть & $\begin{array}{l}\text { В любом городе, в любой рабочей среде будут встречаться все более раз- } \\
\text { ные (суб)культуры, в том числе за счет разрыва поколений. }\end{array}$ \\
\hline $\begin{array}{l}\text { Способность } \\
\text { к (само)обучению }\end{array}$ & $\begin{array}{l}\text { В быстро меняющемся мире человеку придется продолжать обучение в } \\
\text { течение всей жизни, иногда самостоятельно осваивая новые навыки. }\end{array}$ \\
\hline
\end{tabular}

три и вне компании, наличие всех документов. Творческое мышление необходимо для формирования отчетности в соответствии с законодательством, но и с благоприятной точки зрения для бенефициара. Критическое мышление позволяет анализировать необходимость работы с различными контрагентами. Лидерство дает уверенность руководителю в том, что человек компетентен и ему можно доверить разделять бизнес.

Перед образовательными учреждениями не должна стоять задача обучить «профессии», должна быть цель помочь найти предназначение, развить сильные стороны, поставить самореализацию во главу угла.

Новая парадигма и траектория образования должна предложить новые роли для имеющихся компетенций. Обучение бухгалтерскому учету должно включать бизнес-игры, тренинги на решение реальных задач, работу и обсуждение вопросов в мини-группах, моделирование ситуаций с помощью систем виртуальной реальности.

Бухгалтерский учет меняется, развивается МСФО благодаря глобализации. Переход на электронный документооборот предзнаменует отказ от операционистов, обрабатывающих первичную документацию. Налоговые органы имеют свои базы, которые сегодня отображают взаимосвязь контрагентов от первого до послед- него звена. Еще не так давно бухгалтер формировал книгу покупок и продаж вручную, сегодня это формируется в базе, бухгалтер не стоит в очереди на сдачу отчетности, а отправляет все через систему. Программа сама проводит анализ финансовой деятельности организации и отображает динамику развития. Однако система не совершенна. Часто приходят штрафы и пени изза неправильной подвязки данных. В таких условиях инструментарий бухгалтера должен быть значительно шире, чем на начальных этапах становления рыночной экономики. Вопрос автоматизации становится актуальным, и многие воспринимают это исключительно со знаком «минус», объясняя опасениями по поводу исчезновения такой профессии как бухгалтер. Рассматривая вопрос с другой стороны, явным становится то, что бухгалтер должен смещать фокус своего анализа из области бухгалтерского учета. Действительно, за него рутинную работу сделает машина. Более того, бухгалтеру нет необходимости готовить отчеты, поскольку современные системы, такие как ERP (Enterprise resource planning, планирование ресурсов предприятия), позволяют любому руководителю сделать отчет на заказ. Оперативный и достоверный бухгалтерский финансовый учет является драйвером для управленческого учета. Поэтому появляется такой термин как гибридный бухгалтер, высту- 
пающий в роли в качестве аналитика, который честве бухгалтеров, но робот не заменит аналидействительно своим вкладом в анализ и ин- тика, который просчитает все возможные риски терпретацию информации будет способствовать и варианты работы, по крайней мере в ближайулучшению качества управленческих решений. шие 15-20 лет.

В будущем не будет потребности в таком коли-

\section{Библиографический список}

1. Е. Лошкарева, П.Лукша, И.Ниненко, И. Смагин, Д. Судаков. Доклад «Навыки будущего. Что нужно знать и уметь в новом сложном мире»

2. С.А. Стрижов, Е.А. Богатырева, Т. Г. Богатырева «Трансформация государственного управления в условиях новых вызовов»

3. http://atlas100.ru/

4. https://www.banki.ru/news/columnists/?id=10906759 